\title{
A Novel Efficiency Measure Model for Industrial Land Use Based on Subvector Data Envelope Analysis and Spatial Analysis Method
}

\author{
Wei Chen, ${ }^{1}$ Rui He, ${ }^{2}$ and Qun $W u^{3}$ \\ ${ }^{1}$ College of Economics \& Management, Northwest A\&F University, Yangling, Shaanxi 712100, China \\ ${ }^{2}$ Faculty of Geographical Science, Beijing Normal University, Beijing 100875, China \\ ${ }^{3}$ College of Public Administration, Nanjing Agricultural University, Nanjing 210095, China \\ Correspondence should be addressed to Qun Wu; wuqun@njau.edu.cn
}

Received 6 July 2017; Revised 11 September 2017; Accepted 23 November 2017; Published 17 December 2017

Academic Editor: Daniela Paolotti

Copyright (C) 2017 Wei Chen et al. This is an open access article distributed under the Creative Commons Attribution License, which permits unrestricted use, distribution, and reproduction in any medium, provided the original work is properly cited.

\begin{abstract}
With the rapid and unbalanced development of industry, a large amount of cultivated land is converted into industrial land with lower efficiency. The existing research is extensively concerned with industrial land use and industrial development in isolation, but little attention has been paid to the relationship between them. To help address this gap, the paper creates a new efficiency measure method for industrial land use combining Subvector Data Envelope Analysis (DEA) with spatial analysis approach. The proposed model has been verified by using the industrial land use data of 30 Chinese provinces from 2001 to 2013 . The spatial autocorrelation relationship between industrial development and industrial land use efficiency is explored. Furthermore, this paper examines the effects of industrial development on industrial land use efficiency by spatial panel data model. The results indicate that the industrial land use efficiency and the industrial development level in the provinces of eastern region are higher than those of the western region. The spatial distribution of industrial land use efficiency shows remarkable positive spatial autocorrelation. However, the level of industrial development has obvious negative spatial autocorrelation since 2009. The improvement of industrial development has a significant positive impact on the industrial land use efficiency.
\end{abstract}

\section{Introduction}

China's economy steps into the "new normal" phase after transforming itself from an agricultural power to an industrial power. Industrial development has entered a stage of accelerated transformation and upgrading, which plays an important role in the growth of China's economy in the stage of rapid urbanization during the past thirty years [1,2]. Along with it, the industrial land continues to expand and will continue to grow in the next period of time [3-5]. Land used for state-owned construction exceeded $6,000 \mathrm{~km}^{2}$ per year and the proportion of industrial land surpassed 20\% from 2012 to 2014 [6]. In most cities in China, the urban expansion is associated with the changes of China's economic structure [7], especially the industrial economic structure. The proportion of industrial land has already exceeded the reasonable proportion, leading to the imbalance of urban land use structure [8]. Although the proportion of industrial land declines in some large cities such as Beijing and Nanjing, in fact, industrial land gradually shifts to the subcenters of the city. Industrial land still plays an important role in the economic development [9-11]. What is more, due to the different industrial development level in various regions, there is an obvious difference between regions in industrial land use efficiency. Therefore, it is of great importance to study the impact of industrial development and regional relations on industrial land use efficiency. In addition, efforts should be made to push for the intensive use of industrial land, which should alleviate problem in China's industrial development and inhibit the inefficient expansion of industrial land.

Many researchers have analyzed theoretically the industrial land use. The current industrial land system has exerted a significantly positive effect on the development of China's industry and economy, and the influence of China's eastern coastal areas is more obvious [12]. Also, the influence of rural 
industrialization on the development of industrial economy can not be ignored [13]. The industrial land market is an outcome of planned economy color [14-16]. The supply of industrial land with low land price has become one of the cores of industrial land use system [17]. At the same time, there are various preferential policies to encourage large-scale construction of industrial development zones $[18,19]$. The policy combination reduces the production costs of industrial enterprises, accelerates the agglomeration and development of industrial enterprises, and provides an impetus to constant revenue and economic development for central and local governments. The combination of national development strategies and regional land use policies also plays an important role in industrial land expansion [20]. Actually, there is no doubt that these policies lead to some problems, such as the continuous expansion, space imbalance, and inefficient use of industrial land. Industrial land volume rate is generally only $0.3-0.6$, far below the average level of 1.0 in developed countries, and the output of industrial land is also prominently low. Due to the increasing restriction of land resources, the improvement of land use efficiency will be a crucial issue for China to enter into its economic new normal and achieve sustainable development [21, 22].

Some conclusions about the industrial economy of China can be drawn from existing research. The industrial development in China shows a gradient tendency with the economic scale and output showing a gradual decline for industries from eastern China to western China. Definitely, in the context of division and adjustment for international and domestic industries as well as the rapid shift from the eastern coastal regions in China to the central and western regions, it is expected that the central and western regions take industry development as a breakthrough point, realize the rapid development of their own economy, and narrow the economic gap with the eastern region [23]. The industrial model of China is concentration, specialization, and cluster development. The regions with higher level of industrial specialization have a faster industrial development level. Besides, the development in clustered areas is faster than that in nonclustered areas $[24,25]$. Industrial agglomeration has a significant impact on enhancing the competitiveness of hinterland development and forming metropolitan area [26]. Although the industrial clusters can accelerate the process of industrialization, the impact of various types of industrial on the industrialization process is different [27]. Meanwhile, high-tech industry plays a positive role in promoting industrial upgrading and industrialization [28]. In addition, foreign direct investment has a direct impact on the development of China's industrial economy and has obvious regional differences [22, $25,29]$. Therefore, the gap in industrial development has directly affected the industrial land use efficiency in different regions of China [30-32].

Based on the above analysis, we can find that the use and management of China's construction land have planned economy color to some extent. While the marketization in commercial and residential land supply has been achieved, the industrial land market is still undergoing a slow development and suffering from low efficiency, which is closely related to the industrial development of China. However, investigating the interactive relationship between China's industrial development and the utilization efficiency of industrial land is rare. Traditional method of industrialization division can comprehensively measure the economic development from industry, economy, and population [33], but it can be weak in highlighting the characteristics of industrial development. Also, existing related studies can not well analyze regional differences in industrial land use efficiency. In fact, the industrial development of China shows significant regional differences, interregional competition, and cooperation. It is critical to explore the internal rules of industrial development as well as its effect on the efficiency of China's industrial land use by spatial analysis method. Therefore, this paper measures industrial land use efficiency and analyzes the spatial relationship between industrial development level and industrial land use efficiency. Finally, three indicators of industrial development level are used to measure industrial development in different provinces based on spatial analysis method, so as to provide theoretical basis for the improvement of industrial land use efficiency and the coordination of industrial development.

The remainder of this paper is organized as follows. Section 2 describes the methodologies of Subvector DEA model, evaluation index of industrial development level, and spatial measurement model. Data is also presented in this section. Section 3 presents the results. And the conclusions are summarized in Section 4.

\section{Method and Data}

2.1. Subvector DEA Model. The use of DEA model can help measure the efficiency of production technology from the perspective of manufacturers (enterprises or farmers) with the basic principle that the actual production point of the producer deviates from the production possibility boundary, resulting in the loss in efficiency. The inefficiency of production technology is generally attributed to the inefficient management which involves a variety of elements management of production inputs. Differences in the management objectives of different production factors will lead to the differences in the efficiency of different factors. However, it is difficult to determine which inefficient management of production factors leads to low technical efficiency from the perspective of inefficient producer technology which mainly results in the inefficiency of technology [34]. The efficiency of industrial land used in this paper is to analyze the adequacy of industrial land use under the condition that the output and other production input factors are unchanged. Therefore, the industrial land use efficiency is analyzed by Subvector DEA method [35].

Based on regional differences in industrial production, each province in China is considered as an industrial production decision-making unit (DMU), and the production is of the same kind in each province with the same kind of input. Assuming that there are $N$ decision units and that each decision unit has $K$ kinds of input and $M$ kinds of outputs, for decision unit $i$, the column vectors $x_{i}$ and $y_{i}$ are used to denote the input and output, respectively. For all the $N$ decision units, $X$ is used to denote a $K \times N$ input matrix and 
$Y$ is $M \times N$ output matrix. $\theta_{i}^{g}$ denotes the variables of scores of industrial land use efficiency (ILE) in province $i$. The result can be obtained by solving the following linear programming model:

$$
\begin{array}{ll}
\operatorname{ILE}_{i}=\min _{\theta, \lambda} & \theta_{i}^{g} \\
\text { s.t. } & -y_{i}+Y \lambda \geq 0 \\
& \theta_{i}^{g} x_{i}^{g}-X^{g} \lambda \geq 0 \\
& x_{i}^{n-g}-X^{n-g} \lambda \geq 0 \\
& N 1^{\prime} \lambda=1 \\
& \lambda \geq 0 .
\end{array}
$$

According to the first constraint condition, the output of the decision unit $i$ should not be larger than that of the decision-making unit on the production frontier. Under the second constraint condition, matrix $x_{i}^{g}$ and matrix $X^{g}$ only refer to the input of industrial land use. In the third constraint condition, matrix $x_{i}^{n-g}$ and matrix $X^{n-g}$ refer to other input factors in addition to industrial land. The fourth constraint condition is a convex constraint, which indicates that the model is variable returns to scale (VRS). In fact, this model is constant returns to scale (CRS) when there is no convex constraint. Based on the first three constraint conditions, the efficiency of a single industrial production factor is figured out on the condition of current technical level and the output and other input elements unchanged. $\lambda$ is a vector of constants. $\theta_{i}^{g}$ is dimensionless with the range from 0 to 1 . When $\theta_{i}^{g}=1$, the province $i$ is at the production frontiers, which is the effective point of production on the condition that output as well as industrial land input is not reduced. When $\theta_{i}^{g} \neq 1$, the province $i$ is not at the production frontiers and the efficiency of industrial land use reaches zero. Theoretically, there is a possibility that the land can be saved.

2.2. Measurement Method of Industrial Development. In order to reflect the core attributes of industrial development level, economic development of the industry, quality of industrial development, and specialization level of the industry are selected to represent industrial development level (IDL). Correspondingly, IOVP, HTP, and ISD are used as quantitative variables to indicate industrial development. The $I D L$ is figured out by adding the three figures based on their weight. Among them, IOVP is the proportion of industrial added value accounted for in regional GDP in different provinces; HTP denotes the total value of high-tech industry with the proportion of different sectors of manufacturing industry in different provinces, as well as the total proportion it accounts for in manufacturing of different provinces. The high-tech industry mainly covers six categories including medical manufacturing, aircraft, spacecraft, and related equipment manufacturing, electronic and communication equipment manufacturing, computer and office equipment manufacturing, medical equipment and measuring instrument manufacturing, and electronic chemical manufacturing. IDE refers to the total output value of the leading sectors in manufacturing as well as its proportion in the manufacturing sector. The top seven industries were selected as the leading industries in manufacturing. The calculation formula of IDE is as follows:

$$
\mathrm{IDL}=\mathrm{IOVP} \times \alpha+\mathrm{HTP} \times \beta+\mathrm{ISD} \times \gamma,
$$

where $\alpha, \beta$, and $\gamma$ refer to index weight. In this paper, the Delphi method is used to determine the weight of the index. The scoring team is composed of ten experts in the related research fields from College of Economics and Management of Northwest A\&F University, Faculty of Geographical Science of Beijing Normal University, and College of Public Administration of Nanjing Agricultural University. After three rounds of opinion collection and feedback, it finally obtains $\alpha=0.449, \beta=0.347$, and $\gamma=0.204$.

\subsection{Spatial Panel Data Model}

2.3.1. Basic Form of the Model. The basic idea of the spatial panel metrology model is to study the neighbor in the unit space with the spatial definition of weight matrix and to study the neighbor time with the definition of time-delay. The two basic spatial norm coefficients' regression model includes the spatial lag model (SLM) and spatial error model (SEM), based on which Lesage and Elhorst developed Spatial Durbin Model (Spatial Durbin Model) [36-38]. Meanwhile, endogenous variables and exogenous variables with spatial hysteresis were also included. The basic forms of three type of models are as follows.

(1) Spatial Lag Model (SLM)

$$
y=\rho W y+X \beta+\varepsilon
$$

where $y$ represents the dependent variable and $X$ is an exogenous explanatory variable matrix for $n \times k$. $\beta$ denotes the explanatory coefficient. $\rho$ represents the spatial regression correlation coefficient and $W$ is an adjacency weight matrix of $n \times n$ order spaces. Wy means the spatial lag dependent variable, which is used to measure the spatial spillover effects of neighbor in geographical space. $\varepsilon$ represents the random error term vector. Equation (3) is also called Spatial Autoregressive Model (SAR).

\section{(2) Spatial Error Model (SEM)}

$$
y=X \beta+\varepsilon, \quad \varepsilon=\lambda W \varepsilon+\mu,
$$

where $\varepsilon$ represents the random error term vector and $\lambda$ represents the spatial error coefficient of the variable vector of $n \times 1$. Besides, $\mu$ is the random error term vector that follows the normal distribution. The formula is used to measure the spatial dependence of sample observations.

(3) Spatial Durbin Model (SDM)

$$
y=\rho W y+X \beta+W X \theta+\varepsilon .
$$


Compared with (3), (5) contains both the spatial lag of the dependent variable and the space lag of independent variables.

The selection of the three models above is mainly based on the test of Wald, which means if the $P$ values of Wald spatial_lag and Wald_spatial_error are significant, then SDM is applicable; if the value of Wald_spatial_lag is insignificant while the value of LM-lag is significant, then SLM is applicable; if the value of Wald_spatial_lag is insignificant while the value of LM-error is significant, then SEM is applicable. However, once one of the conditions is not met, for instance, Wald_spatial_error value is not significant, LMerror value is not significant either, and the two models point to the contrary, then SDM is applicable, which contains the information of SLM and SEM [39, 40].

2.3.2. Selection of Variables. In order to examine the impact of industrial development on industrial land use efficiency, industrial output value proportion (IOVP), high technology industry output proportion (HTP), and industrial specialization index (ISD) are chosen as the explanatory variables. $G P R R, B M P, F N P$, and other factors are included as the control variable from the macro perspective. The level of regional economic development (GPRR), denoted by GDP per capita ( $10^{4}$ yuan), is the ratio of GDP to the resident population at the end of the year in each province. The annual production value of the region shall be converted to the price level in 2001. The scale of business enterprise (BMP) is denoted by the proportion of the profits of industrial enterprises above designated size to gross output value of industries above designated size. The ownership structure of industrial enterprises (FNP) is denoted by the proportion of the number of foreign, Hong Kong, Macao, and Taiwan invested industrial enterprises to the number of industrial enterprises above designated size.

2.4. Data Source. Because the data of Hong Kong, Macao, Taiwan, and Tibet are difficult to obtain, this paper only chooses 30 provinces in China as decision-making units for industrial production when measuring the industrial land use efficiency. Industrial land area $(G)$, labor force scale $(L)$, and fixed capital stock $(K)$ are variables for industrial production input, while industrial output $(Y)$ is a variable for industrial production output. The data of industrial output, number of employees, fixed capital stock, and industrial land area in each province come from Statistical Yearbook of China's Cities (2002-2014), Statistical Yearbook of China's Urban Construction (2001-2013), and Statistics Yearbook of China's Regional Economy (2002-2014).

When calculating the proportion of industrial output value (IOVP), proportion of high-tech industry output value (HTP) and industrial specialization index (ISD) as well as the regional economic growth (GPRR), scales of industrial enterprises (BMP and FNP) are collected from the Statistical Yearbook of China (2002-2014), Statistical Yearbook of China's High-Tech Industry (2002-2014), and Statistical Yearbook of China's Provinces (2002-2014).

\section{Results and Discussion}

3.1. The Efficiency of Industrial Land Use. This paper focuses on the comprehensive technical efficiency of industrial land use by using GAMS 22.0 and selects CRS model as the calculation model to figure out the industrial land use efficiency. Figure 1 shows industrial land use efficiency in 2001, 2005, 2009, and 2013. The highest efficiency is of Guangdong and Tianjin from 2001 to 2013. There is virtually no existence of land investment redundancy in the two provinces. Shanghai, Zhejiang, Jiangsu, Fujian, and other eastern coastal provinces are at the production frontier and the industrial land use efficiency is relatively high in several years. The efficiency of provinces in central and western China is relatively low, especially the provinces in the northwestern, namely, Ningxia and Qinghai, where the industrial land use efficiency is the lowest. This may be due to the insufficient productivity and excessive land input.

From the perspective of sequential variation, industrial land use efficiency in China from 2001 to 2013 has not shown a gradual state of equilibrium. There emerges an increasing trend that the provinces of eastern coastal provinces are becoming more and more efficient in industrial land use, especially in the land use in the region of Bohai rim, Yangtze River Delta, and Pearl River Delta. In the central and western regions, the efficient industrial land use only in Chengdu and Chongqing provinces is gradually stable and efficient. This is because, for one thing, based on the existing urban construction land management system, there are a high land development intensity and a relatively small supply of industrial land in the eastern coastal provinces; for another, the highest level of industrial structure and relatively high productivity as well as the improving policies, namely, land use threshold, supervision, and management mechanism, are all the impetus for this achievement. However, the construction land area of the central and western provinces is relatively small, and the industrial land area is increasing faster than the increase of its industrial output capacity. At the same time, these provinces have lower level of industrial structure and larger land consumption per unit output. Only under the strict control of land supply and constantly improving the level of industrial development and quality, in order to achieve the sustainable utilization of industrial land, the sustainable use of industrial land can be achieved only through strictly controlling land supply and improving the level and quality of industrial development.

3.2. The Level of Industrial Development. Figure 2 shows industrial development level of China in the years of 2001, 2005, 2009, and 2013. Generally speaking, the level of China's industrial development is increasing during the period. The degree of equilibrium increases continuously from the eastern coast to the central and western regions. Coastal provinces and cities including Guangzhou, Tianjin, and Jiangsu ranked the first in industrial development, while the development level in Hainan, Hunan, and Guangxi is relatively low.

Judging from the changes in different provinces, one can easily draw a conclusion that the distribution of industrial development in China shows a tendency of decline in the eastern coastal provinces and a tendency of increase in the central and western provinces. The provinces with high industrial development levels in 2001 were mainly concentrated in the eastern regions, including Bohai Rim Region, the 

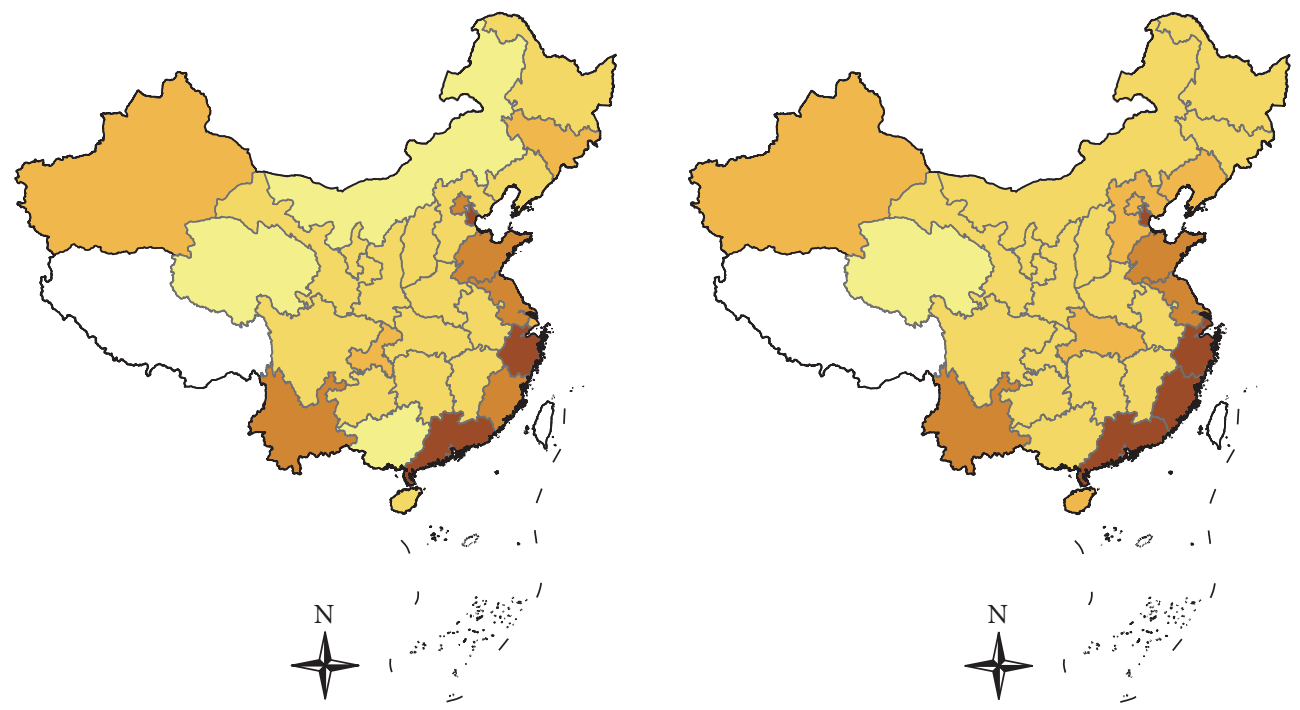

$(\mathrm{KM})$

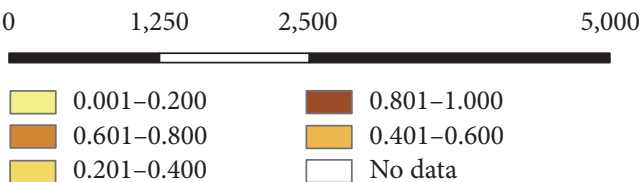

(a)
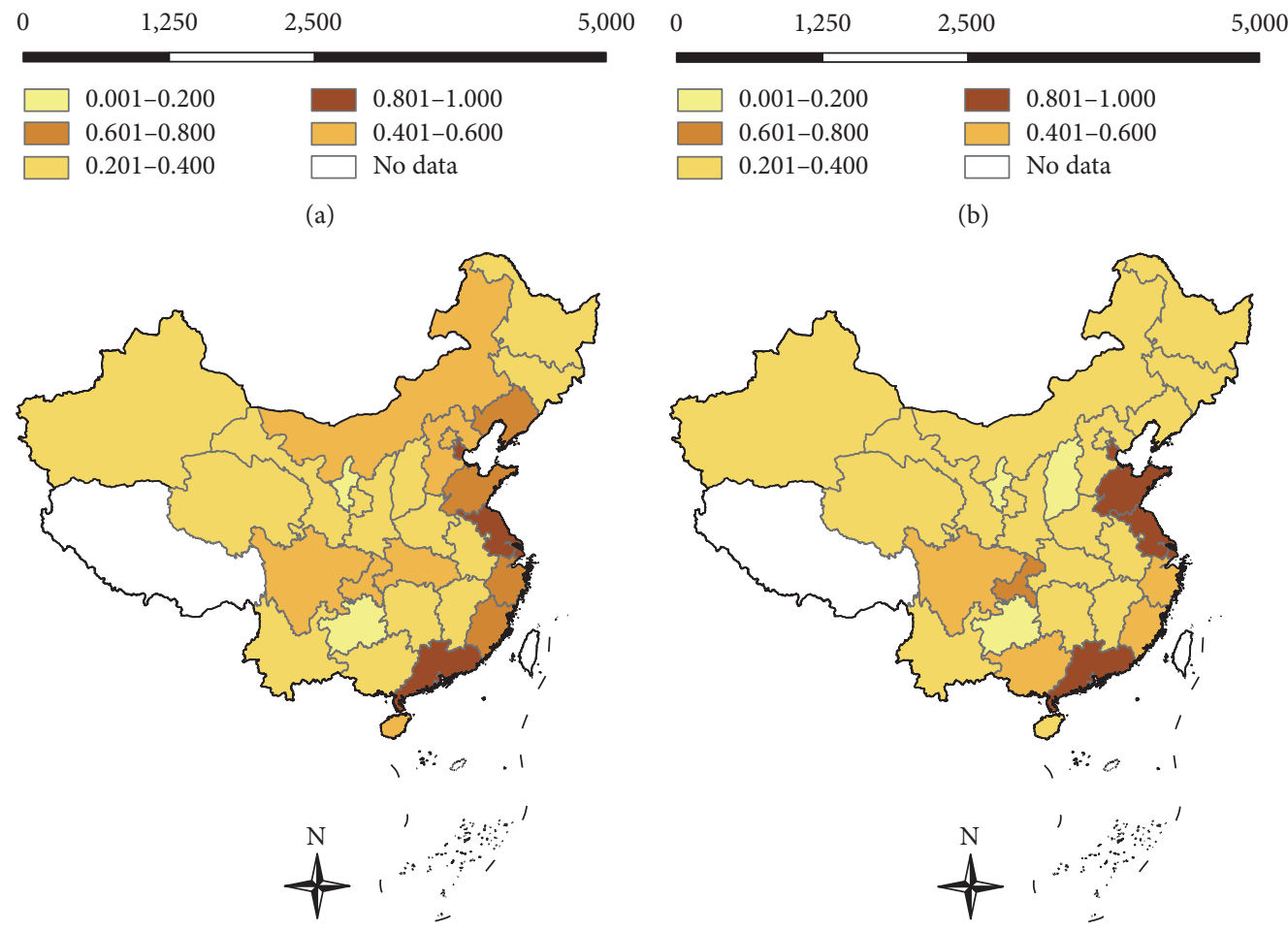

(b)

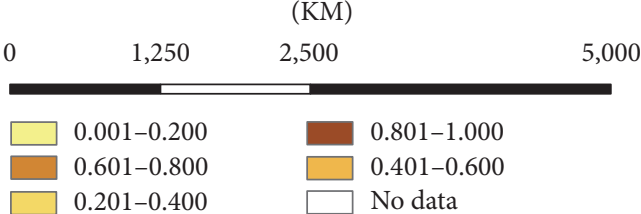

(c)

$$
\begin{aligned}
& 0.801-1.000 \\
& 0.401-0.600 \\
& \text { No data }
\end{aligned}
$$
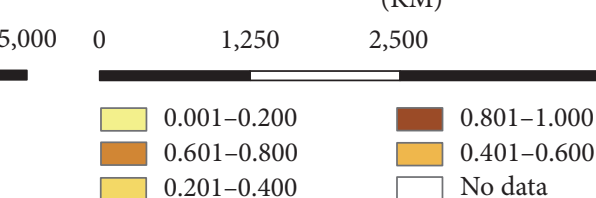

(d)

Figure 1: Industrial land use efficiency of 2001 (a), 2005 (b), 2009 (c), and 2013 (d).

Yangtze River Delta Region, and the Pearl River Delta Region. In 2013, provinces with high industrial development levels are mainly concentrated in the central and western regions. This is due to the implementation of "Guiding Opinions of the State Council on Central and Western Regions Undertaking of Industrial Transfer." In the context of industrial transformation and upgrading, the third industries in the eastern provinces have developed rapidly, and the proportion 

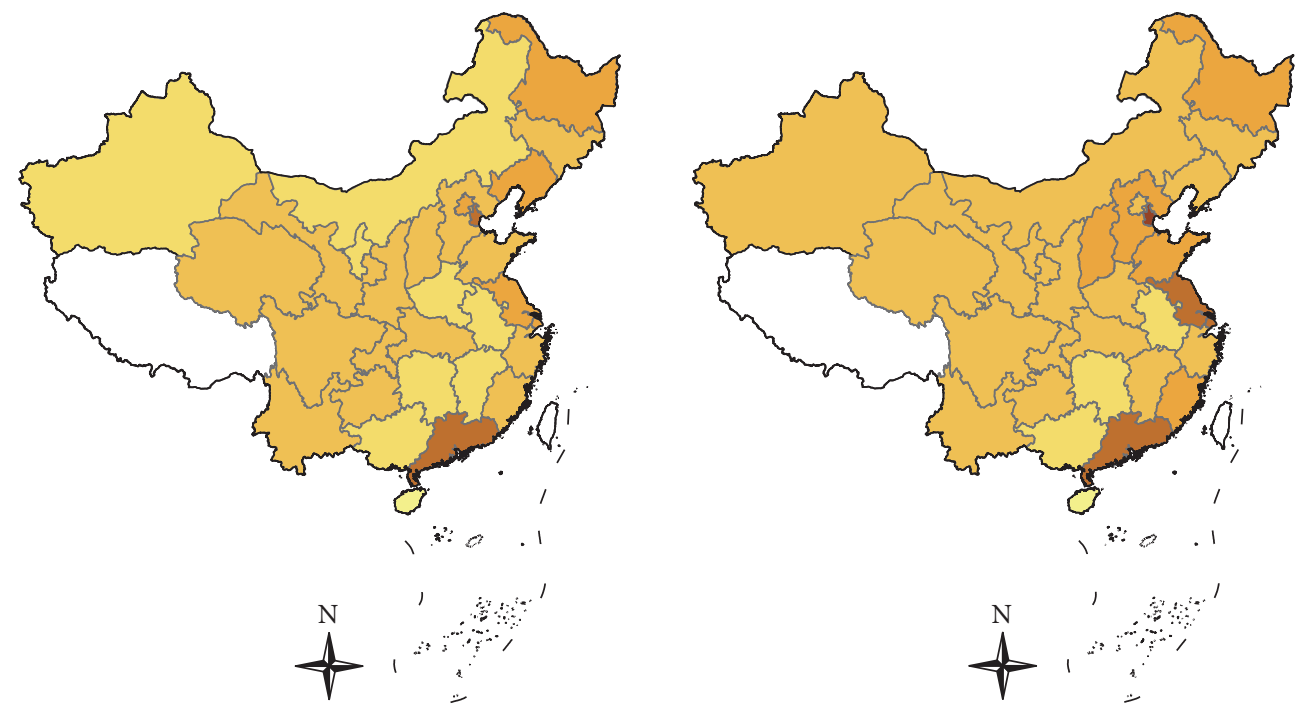

(KM)

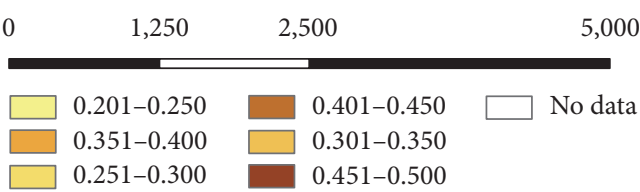

(a)
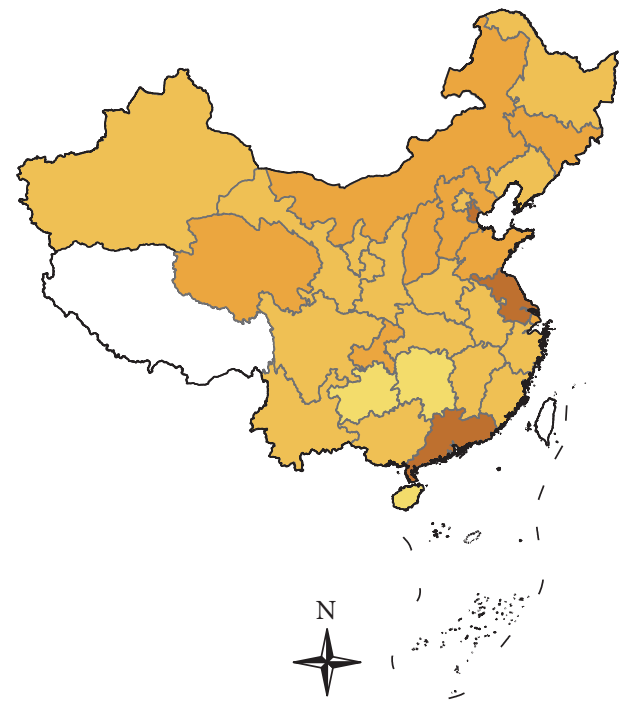

$(\mathrm{KM})$

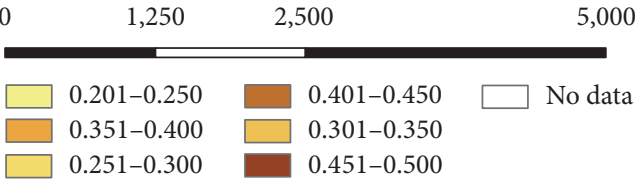

(c)
$(\mathrm{KM})$

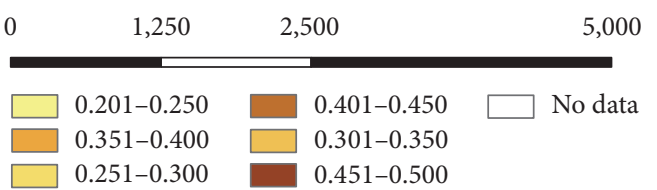

(b)

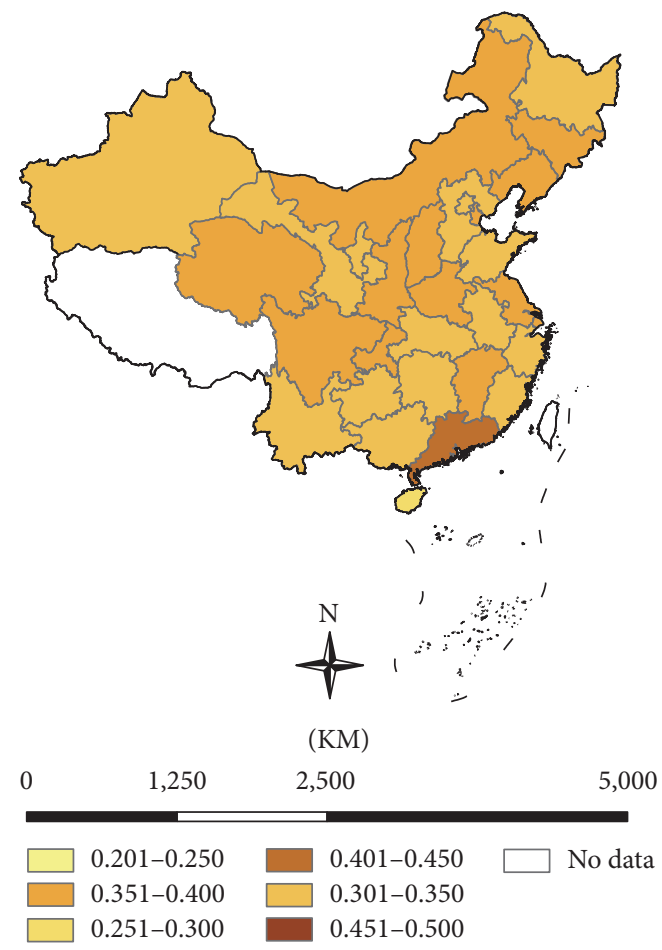

(d)

FIGURE 2: Industrial development level of 2001 (a), 2005 (b), 2009 (c), and 2013 (d).

of the second industries has gradually declined. Despite the continuous industrial development in provinces of the central, western, and northeastern region, the proportion of high-tech enterprises is still relatively low. Most of the industries in these regions are the low-end manufacturing industries that have been turned out and restricted in the eastern region. With the implementation of policies such as the industrial transformation and upgrading and shifting 
from labor-intensive industry to service economy, the driving role of industrial development in the surrounding provinces is weakening. Therefore, more support should be given to improve the undertaking capacity of industries in the central and western region of China, such as the rise of central China and revitalization of northeast old industrial base. Actually, the central and western provinces should also continuously make efforts to increase research and technological import, narrow the industrial gap with the eastern coastal provinces, and achieve sustainable industrial development.

3.3. Analysis of Global Spatial Autocorrelation. Moran's I of ILE, IDL, IOVP, HTP, and ISD is shown in Table 1, which is calculated by Geoda 1.8. The value range of Moran is between -1 and 1 . The bigger the absolute value is, the higher the degree of industrial development correlation or industrial land use efficiency between different provinces and spatial autocorrelation is. Moran's I is positive, which means there exists positive spatial autocorrelation of the economic phenomena. Moran's I is negative, indicating that the spatial autocorrelation is negative. When Moran's I is zero, it presents a random spatial layout and is unrelated.

Moran's I of industrial land use efficiency is positive and statistically significant at 5\% and 1\% level from 2001 to 2013, indicating that an obvious positive autocorrelation in spatial distribution of industrial land use efficiency and every province is significantly affected by the neighboring provinces. From the overall development trend, spatial autocorrelation in industrial land use efficiency in each province shows a tendency that increased firstly and then decreased after stability. The spatial autocorrelation of industrial land use efficiency shows an increasing trend in each province from 2001 to 2004, and Moran's I increases from 0.2119 to 0.4043 . During this period, it shows a rapid expansion of industrial land in China and a rectification of development zones. Both the rapid development of industrial economy and timely macro-control of land had positive effect on the promotion and balanced development of industrial land use efficiency. From 2005 to 2010, it exhibits a relatively stable trend in all provinces despite occasional fluctuations of Moran's I between 0.3299 and 0.4074 . China's industrial economy witnesses a continuing expansion and development during this period. However, under the influence of a global economic crisis, a large number of export-oriented industrial enterprises have been seriously affected, causing relatively obvious differences in industrial land use efficiency among provinces in the short term. From 2011 to 2013, industrial land use efficiency of each province shows a significant downward trend and Moran's I falls from 0.2879 to 0.1934. Since the implementation of the "Twelfth Five-Year Plan," industrial transformation is accelerating in the eastern region. In addition, the implementation of the strategy of central China's rise and the revitalization of the northeast old industrial base and other regional industrial development strategies has led to an increasingly obvious difference in the industrial land use efficiency among different provinces. Furthermore, the imbalance is tilt due to a continuing decline in prices of energy and steel together with a prior heavy impact on industrial economic structure in some central and western provinces.
Moran's I of the Industrial Development Level Index (IDL) is negative and it does not pass the test with significance level being 10\% from 2002 to 2008. Therefore, we can not determine the spatial correlation in industrial development level among different provinces. However, it passes the test at 5\% significance level from 2009 to 2013; that is, the level of industrial development shows significant spatial negative correlation among provinces.

Judging from the value and significance degree of Moran's I, although regional differences exist in China's industrial development, there are no significant differences between adjacent areas, especially in advanced industrial provinces and their neighboring provinces before 2009. However, after 2009, with the accelerated development of modern manufacturing, high-tech industry, and other industries, there emerges a significant Matthew effect between different regions where industrially advanced provinces have a greater advantage in terms of attracting investment and concentrating development, playing a negative role in the development of its neighboring regions. It can also suggest that the Matthew effect in the industrial development level among different provinces is mainly attributed to the overall development of the industry. Of course, there is no denying the fact that industrial advanced areas have played a positive role in the agglomeration development of leading industries and the proliferation of high-tech industries in the neighboring regions.

\subsection{Analysis of Spatial Econometric}

3.4.1. The Selection of the Model. Taking the industrial land use efficiency (ILE) in 30 different provinces from 2001 to 2013 as the explanatory variables, this paper carries out the ordinary least squares estimation and the model selection by Matlab R2010a software. This research studies 30 provinces in China as a whole. Therefore, there is no need to deduce the overall property from the specific property of single province. Fixed-effect model should be applied.

The estimated results of ordinary least squares and spatial correlation test are showed in Table 2. It presents the fact that the effect of model space fixation and time fixation is significant from the LR-test statistics of spatial fixation effect and the time fixation effect. Judging from the estimated results of LM-lag, LM-error, Robust LM-lag, and Robust LMerror, the SLM model is more suitable than the SEM model. In addition, the statistics of LM-lag and LM-error are significant in the time fixed model and double fixed model. However, $R^{2}$ of time fixed model is much larger than that in the double fixed model, so the former model fitting is better.

The test results of the SDM model are showed in Table 3. Both the values of Wald_spatial_lag and Wald_spatial_error have passed the test at the significant level of $5 \%$ in the spatial fixed model, time fixed model, and double fixed model, indicating that the SDM model with three fixed effects is suitable for the study of the factors affecting the utilization efficiency of industrial land. However, the significant levels of the Wald_spatial_lag and Wald_spatial_error with the time fixed model are relatively high in model 2. Therefore, SDM model is preferred in the paper in the estimation based on the above test results. 
TABLE 1: Moran's I of industrial land use efficiency and industrial development level.

\begin{tabular}{lccccc}
\hline Year & ILE & IDL & IOVP & ISD & HTP \\
\hline 2001 & $0.212^{* *}(2.180)$ & $-0.186^{*}(-1.265)$ & $-0.030(0.108)$ & $0.233^{* *}(2.136)$ & $0.185^{* *}(2.026)$ \\
2002 & $0.221^{* *}(2.115)$ & $-0.157(-1.101)$ & $-0.023(0.142)$ & $0.156^{*}(1.703)$ & $0.258^{* *}(2.454)$ \\
2003 & $0.373^{* * *}(3.392)$ & $-0.120(-0.726)$ & $-0.016(0.225)$ & $0.193^{* *}(1.905)$ & $0.221^{* *}(2.208)$ \\
2004 & $0.404^{* * *}(3.718)$ & $-0.110(-0.644)$ & $-0.032(0.074)$ & $0.166^{* *}(1.687)$ & $0.254^{* *}(2.354)$ \\
2005 & $0.323^{* * *}(2.972)$ & $-0.078(-0.414)$ & $-0.007(0.254)$ & $0.268^{* *}(2.501)$ & $0.258^{* *}(2.510)$ \\
2006 & $0.252^{* *}(2.484)$ & $-0.081(-0.422)$ & $-0.048(-0.112)$ & $0.237^{* *}(2.298)$ & $0.274^{* * *}(2.606)$ \\
2007 & $0.377^{* * *}(3.483)$ & $-0.060(-0.251)$ & $-0.032(0.085)$ & $0.163^{*}(1.612)$ & $0.220^{* *}(2.411)$ \\
2008 & $0.332^{* * *}(3.206)$ & $-0.103(-0.574)$ & $-0.055(-0.216)$ & $0.184^{* *}(1.811)$ & $0.200^{* *}(2.110)$ \\
2009 & $0.325^{* * *}(3.026)$ & $-0.225^{* *}(-1.625)$ & $-0.063(-0.259)$ & $0.179^{* *}(1.726)$ & $0.203^{* *}(2.097)$ \\
2010 & $0.407^{* * *}(3.786)$ & $-0.284^{* * *}(-2.108)$ & $-0.041(0.000)$ & $0.217^{* *}(2.074)$ & $0.235^{* *}(2.362)$ \\
2011 & $0.288^{* *}(2.752)$ & $-0.264^{* *}(-1.979)$ & $-0.011(0.273)$ & $0.137^{*}(1.465)$ & $0.222^{* *}(2.212)$ \\
2012 & $0.293^{* * *}(2.745)$ & $-0.320^{* * *}(-2.324)$ & $-0.033(0.046)$ & $0.333^{* * *}(2.980)$ & $0.266^{* * *}(2.624)$ \\
2013 & $0.193^{* *}(2.004)$ & $-0.364^{* * *}(-2.679)$ & $-0.040(-0.036)$ & $0.366^{* * *}(3.200)$ & $0.219^{* *}(2.225)$ \\
\hline
\end{tabular}

Note. (1) Numbers in parentheses are $Z$ values; (2) ***, **, and * denote statistical significance at the levels of $1 \%, 5 \%$, and $10 \%$, respectively.

TABLE 2: Results of OLS estimation and spatial correlation testing.

\begin{tabular}{|c|c|c|c|c|c|c|c|}
\hline \multirow[b]{2}{*}{ Variable } & \multicolumn{3}{|c|}{ Model 1} & \multirow[b]{2}{*}{ Variable } & \multicolumn{3}{|c|}{ Model 2} \\
\hline & $\begin{array}{c}\text { Spatial } \\
\text { fixed }\end{array}$ & $\begin{array}{l}\text { Time } \\
\text { fixed }\end{array}$ & $\begin{array}{c}\text { Double } \\
\text { fixed }\end{array}$ & & $\begin{array}{l}\text { Spatial } \\
\text { fixed }\end{array}$ & $\begin{array}{l}\text { Time } \\
\text { fixed }\end{array}$ & $\begin{array}{c}\text { Double } \\
\text { fixed }\end{array}$ \\
\hline \multirow[t]{3}{*}{$I D L$} & $0.722^{* * *}$ & $1.322^{* * *}$ & $1.348^{* * *}$ & $I O V P$ & 0.088 & $0.466^{* * *}$ & 0.197 \\
\hline & & & & $H T P$ & $1.121^{* * *}$ & $0.856^{* * *}$ & $1.131^{* * *}$ \\
\hline & & & & $I S D$ & $0.369^{* *}$ & 0.041 & $0.402^{* *}$ \\
\hline GPRR & -0.008 & $0.115^{* * *}$ & $0.075^{* * *}$ & $G P R R$ & 0.011 & $0.087^{* * *}$ & $0.035^{*}$ \\
\hline$B M P$ & 0.002 & $-0.154^{*}$ & -0.040 & $B M P$ & -0.110 & -0.042 & -0.134 \\
\hline$F N P$ & 0.029 & $0.322^{* * *}$ & $0.068^{*}$ & $F N P$ & 0.036 & $0.267^{* * *}$ & 0.051 \\
\hline$R 2$ & 0.033 & 0.656 & 0.106 & $R^{2}$ & 0.068 & 0.570 & 0.075 \\
\hline Durbin-Watson & 1.887 & 2.270 & 2.073 & Durbin-Watson & 2.003 & 2.434 & 2.010 \\
\hline LM-lag & 0.490 & $6.035^{* *}$ & $6.579^{* *}$ & LM-lag & 0.232 & $4.098^{* *}$ & $3.301^{* *}$ \\
\hline Robust LM-lag & 0.520 & 1.012 & $2.961^{*}$ & Robust LM-lag & 1.515 & $8.027^{* * *}$ & 0.980 \\
\hline LM-error & 0.657 & $5.459^{* *}$ & $9.513^{* * *}$ & LM-error & 0.514 & 0.316 & $4.222^{* *}$ \\
\hline Robust LM-error & 0.687 & 0.436 & $5.895^{* *}$ & Robust LM-error & 1.796 & $4.246^{* *}$ & 1.900 \\
\hline $\begin{array}{l}\text { Spatial fixation effect } \\
\text { LR-test }\end{array}$ & & & $465.632^{* * *}$ & $\begin{array}{l}\text { Spatial fixation } \\
\text { effect LR-test }\end{array}$ & & & $372.976^{* * *}$ \\
\hline $\begin{array}{l}\text { Time fixation effect } \\
\text { LR-test }\end{array}$ & & & $65.005^{* * *}$ & $\begin{array}{c}\text { Time fixation effect } \\
\text { LR-test }\end{array}$ & & & $24.480^{* *}$ \\
\hline
\end{tabular}

Note. $* * *, * *$, and $*$ denote statistical significance at the levels of $1 \%, 5 \%$, and $10 \%$, respectively.

TABLE 3: Wald test results of SDM.

\begin{tabular}{|c|c|c|c|c|c|c|}
\hline \multirow[b]{2}{*}{ Statistic } & \multicolumn{3}{|c|}{ Model 1} & \multicolumn{3}{|c|}{ Model 2} \\
\hline & $\begin{array}{l}\text { Spatial } \\
\text { fixation }\end{array}$ & $\begin{array}{l}\text { Time } \\
\text { fixation }\end{array}$ & $\begin{array}{l}\text { Double } \\
\text { fixation }\end{array}$ & $\begin{array}{l}\text { Spatial } \\
\text { fixation }\end{array}$ & $\begin{array}{c}\text { Time } \\
\text { fixation }\end{array}$ & $\begin{array}{l}\text { Double } \\
\text { fixation }\end{array}$ \\
\hline Wald_spatial_lag & $30.025^{* * *}$ & $44.928^{* * *}$ & $19.337^{* * *}$ & $12.974^{* *}$ & $103.449^{* * *}$ & $18.056^{* * *}$ \\
\hline Wald_spatial_error & $28.499^{* * *}$ & $43.220^{* * *}$ & $13.818^{* * *}$ & $12.594^{* *}$ & $102.951^{* * *}$ & $16.109^{* *}$ \\
\hline
\end{tabular}

Note. $* * *, * *$, and $*$ denote statistical significance at the levels of $1 \%, 5 \%$, and $10 \%$, respectively. 
TABLE 4: Estimate results of time fixation effect space panel data model.

\begin{tabular}{|c|c|c|c|c|c|c|c|}
\hline \multirow{2}{*}{ Variable } & \multicolumn{3}{|c|}{ Model 1} & \multirow{2}{*}{ Variable } & \multicolumn{3}{|c|}{ Model 2} \\
\hline & SLM & SEM & SDM & & SLM & SEM & SDM \\
\hline \multirow[t]{3}{*}{$I D L$} & $1.530^{* * *}$ & $1.499^{* * *}$ & $1.373^{* * *}$ & $I O V P$ & $0.580^{* * *}$ & $0.514^{* * *}$ & $0.856^{* * *}$ \\
\hline & & & & HTP & $0.847^{* * *}$ & $0.789^{* * *}$ & $0.605^{* * *}$ \\
\hline & & & & $I S D$ & 0.049 & 0.036 & $0.179^{*}$ \\
\hline$G P R R$ & $0.108^{* * *}$ & $0.121^{* * *}$ & $0.122^{* * *}$ & $G P R R$ & $0.083^{* * *}$ & $0.091^{* * *}$ & $0.091^{* * *}$ \\
\hline$B M P$ & -0.137 & $-0.145^{*}$ & -0.033 & $B M P$ & -0.002 & -0.024 & -0.005 \\
\hline$F N P$ & $0.277^{* * *}$ & $0.259^{* * *}$ & $0.256^{* * *}$ & FNP & $0.234^{* * *}$ & $0.257^{* * *}$ & $0.224^{* * *}$ \\
\hline \multirow[t]{3}{*}{$W^{*} I D L$} & & & $-0.949^{* *}$ & $W^{*} I O V P$ & & & $-1.005^{* * *}$ \\
\hline & & & & $W^{*} H T P$ & & & $1.500^{* * *}$ \\
\hline & & & & $W^{*} I S D$ & & & $0.551^{* * *}$ \\
\hline$W^{*} G P R R$ & & & $-0.086^{* * *}$ & $W^{*} G P R R$ & & & $-0.056^{* *}$ \\
\hline$W^{*} B M P$ & & & 0.050 & $W^{*} B M P$ & & & $-0.379^{*}$ \\
\hline$W^{*} F N P$ & & & $0.527^{* * *}$ & $W^{*} F N P$ & & & $0.403^{* * *}$ \\
\hline$R^{2}$ & 0.666 & 0.658 & 0.701 & $R^{2}$ & 0.580 & 0.574 & 0.668 \\
\hline Adj. $R^{2}$ & 0.656 & 0.654 & 0.696 & Adj. $R^{2}$ & 0.574 & 0.570 & 0.663 \\
\hline
\end{tabular}

Note. $* * *, * *$, and $*$ denote statistical significance at the levels of $1 \%, 5 \%$, and $10 \%$, respectively.

3.4.2. Result of the SDM Model. In the estimation of SDM model with time fixed effect by Matlab R2010a, the SEM model and the SLM model with time fixed effect are simultaneously employed for comparison. As is shown in Table 4, the goodness of fit of SDM model is the highest with the best explanatory ability and the SLM model is slightly higher than the SEM model.

Different factors have different effects on industrial land use efficiency as a result of the estimation of SDM model. In model 1 , the estimated coefficient of IDL is significantly positive, indicating that the improvement of industrial development imposes a positive impact on the industrial land use efficiency. $1 \%$ of the industrial development level can increase the utilization efficiency of industrial land by $1.373 \%$. The improvement of industry development is accompanied the upgrading and optimizing of the overall scale of industrial economy, the level of industry, and the production skills, which contributes to an increasingly effective way of land use. In model 2, the estimated coefficient of the variable of industrial output value proportion (IOVP) is positive and passes the test by the significance level at $1 \%$, showing that the increase of IOVP has a significant positive effect on the improvement of industrial land use efficiency. The increase of IOVP reveals that the dominant position of industry in the economy has been increasing, and the advantages of industrial agglomeration have gradually formed in the process of industrial production's adjustment and optimization. The land use strategy with industrial domain as the core has gradually shifted towards the goal of intensive utilization in the competition with other construction land supply. The estimated coefficient of the variable of High Technology Industry Output Value Proportion (HTP) is positive with the statistically significance level, at $1 \%$, showing that the increase of HTP has a significant positive effect on the improvement of industrial land use efficiency. Higher HTP reflects higher quality of regional industrial development, higher level of the industrial structure, and higher added value of products in high-tech enterprises, as well as better enterprise profitability and more unit land outputs. The estimated coefficient of the variable of industrial specialization index (ISD) is positive at the significant level of $10 \%$, which indicates that the increase of leading industries output value proportion has a significance positive effect on the improvement of industrial land use efficiency. Higher leading industries output value proportion means a more obvious advantage of regional industry agglomeration and an increase in land scale returns. By comparing of the three indicators of industrial development level, it is found that the greatest effect on the industrial land use efficiency is the degree of industrial economic development, followed by the quality of industrial development and finally the degree of industrial specialization.

With regard to the quantitative analysis result of control variables, Per capita Gross Regional Product (GPRR) is positive in the two models, which shows that the increase of GPRR has a significant positive effect on the improvement of industrial land use efficiency at the significant level of 1\%. Regions with high economic development levels have a better industry structure, where the local government has more financial funds invested in the construction of industrial infrastructure and the enhancement of the quality of labor and managerial personnel. Moreover, construction land resources are relatively scarcer and more expensive in developed areas. All the external factors jointly promote the improvement of industrial land use efficiency. High level of economic development also means better market economy mechanism, which is an important guarantee for economic agglomeration development, industry scale development, and absorption of foreign investment. The proportions of large and medium-sized industrial enterprises above designated size (BMP) are both negative in the two models and fail the significance test, indicating that the scale of industrial 
enterprises has no significant effect on the industrial land use efficiency. Generally speaking, the large-scale enterprises with complete departmental settings and high management level and personnel quality are beneficial for improving industrial land use efficiency. The small enterprises, whose capital is constrained, can make intensive utilization of land more effectively and improve industrial land use efficiency. The proportions of foreign-invested and Hong Kong, Macao, Taiwan invested (FNP) industrial enterprises are both positive in the two models at the significance level of $1 \%$. On the one hand, foreign direct investment has a positive effect on industrial land use efficiency. On the other hand, Hong Kong, Macao, and Taiwan enterprises with wholly foreignowned or joint venture are advanced industries which have a higher level of management and salary standard, and more advanced industries can better enhance the enthusiasm of employees and potential, which has a positive impact on industrial land use efficiency. At the same time, foreigninvested and Hong Kong, Macao, Taiwan invested enterprises have spillover effect, which can prompt neighboring enterprises and enterprises of same types to learn advanced production technology and management skill.

\section{Conclusion and Policy Implications}

This paper measures the industrial land use efficiency of 30 provinces in China from 2001 to 2013 based on the Subvector Data Envelope Analysis (DEA) model. Then the spatial autocorrelation relationship between the industrial development and the industrial land use efficiency is explored. Furthermore, spatial panel data models are adopted to examine the effects of industrial development on industrial land use efficiency. The conclusions are as follows.

(1) The efficiency of industrial land and the level of industrial development in the eastern provinces are higher than those in the western provinces. Along with the national regional development strategy and industrial transfer, the development level of the industry in the midwest provinces continues to improve. Industrial land use efficiency of eastern regions is increasing because of differences of resource scarcity, industrial level, and management mechanism between the two regions.

(2) The spatial distribution of industrial land use efficiency shows remarkable positive spatial autocorrelation. The industrial land use efficiency in each province is significantly affected by the industrial land use efficiency in neighboring provinces, and the spatial autocorrelation appears to increase first and then decrease after stability. Since 2009, industrial development level has obvious negative spatial autocorrelation characteristics and has shown a trend of strengthening. Though the driving effect of eastern coastal provinces on neighboring provinces is weakening, advanced industrial regions still have positive effect on neighboring regions in leading industrial cluster development and the spread of high-tech industries.

(3) The improvement of industrial development has a significant positive impact on the efficiency of industrial land use. The most important factor to improve the utilization efficiency of industrial land is the degree of industrial economic development, followed by the quality of industrial development and, finally, the degree of industrial specialization. Meanwhile, the improvement of regional economy and the rise in foreign and Hong Kong, Macao, and Taiwan investment have positive and significant influence on industrial land use efficiency as well.

Based on the above conclusions, different regions should pay more attention to the influence of their neighboring regions. Therefore, different regions not only avoid the negative effects of Matthew, but also use the spillover effect to develop high-tech industries and improve their specialization degree.

There are also some limitations regarding the data in this research. The industrial development level and industrial land use efficiency do not take into account the industry type, resource endowment, and the matching relations among regions, which will be discussed in the following study in order to provide a more comprehensive theoretical basis for the improvement of China's industrial land use efficiency.

\section{Conflicts of Interest}

The authors declare that there are no conflicts of interest regarding the publication of the paper.

\section{Acknowledgments}

This study was funded by the National Natural Science Foundation of China (71503200, 71233004, and 71603120); the Natural Science Basic Research Program of Shaanxi Province (2016JQ7003); the Fundamental Research Funds for the Central Universities (2452015231, 2017RYWB01, and 2017RWYB06); and the Research Start-Up Funds of Northwest A\&F University (Z109021611, 2452016161).

\section{References}

[1] Y. Fang, R. P. Côté, and R. Qin, "Industrial sustainability in China: Practice and prospects for eco-industrial development," Journal of Environmental Management, vol. 83, no. 3, pp. 315328, 2007.

[2] L. H. T. Choy, Y. Lai, and W. Lok, "Economic performance of industrial development on collective land in the urbanization process in China: Empirical evidence from Shenzhen," Habitat International, vol. 40, pp. 184-193, 2013.

[3] C. Ding, "Land policy reform in China: Assessment and prospects," Land Use Policy, vol. 20, no. 2, pp. 109-120, 2003.

[4] M. Tan, X. Li, H. Xie, and C. Lu, "Urban land expansion and arable land loss in China - A case study of Beijing-Tianjin-Hebei region," Land Use Policy, vol. 22, no. 3, pp. 187-196, 2005.

[5] Q. Jin, X. Deng, Z. Wang, C. Shi, and X. Li, "Analysis and projection of the relationship between industrial structure and land use structure in China," Sustainability, vol. 6, no. 12, pp. 9343-9370, 2014.

[6] Ministry of Land and Resources of China, China Land and Resources Statistical Yearbook 2015, Geological Publishing House, Beijing, China, 2016. 
[7] X. Deng, J. Huang, S. Rozelle, and E. Uchida, "Economic growth and the expansion of urban land in China," Urban Studies, vol. 47, no. 4, pp. 813-843, 2010.

[8] L. Shi, Y. Wu, and X. Zhang, "Study on the proportion of industrial land in city of zhejiang province," in Proceedings of the 18th International Symposium on Advancement of Construction Management and Real Estate, CRIOCM 2013, pp. 121-129, October 2013.

[9] J. Cheng, J. Turkstra, M. Peng, N. Du, and P. Ho, "Urban land administration and planning in China: Opportunities and constraints of spatial data models," Land Use Policy, vol. 23, no. 4, pp. 604-616, 2006.

[10] J. Chen, J. Gao, F. Yuan, and Y. D. Wei, "Spatial determinants of urban land expansion in globalizing Nanjing, China," Sustainability, vol. 8, no. 9, article no. 868, 2016.

[11] C. Sun, C. Sun, Z. Yang, J. Zhang, and Y. Deng, "Urban land development for industrial and commercial use: A case study of Beijing," Sustainability, vol. 8, no. 12, article no. 1323, 2016.

[12] X. Zheng, B. Geng, X. Wu, L. Lv, and Y. Hu, "Performance evaluation of industrial land policy in China," Sustainability, vol. 6, no. 8, pp. 4823-4838, 2014.

[13] Y. Xie, Y. Mei, T. Guangjin, and X. Xuerong, "Socio-economic driving forces of arable land conversion: a case study of Wuxian City, China," Global Environmental Change, vol. 15, no. 3, pp. 238-252, 2005.

[14] L. Tian and W. Ma, "Government intervention in city development of China: A tool of land supply," Land Use Policy, vol. 26, no. 3, pp. 599-609, 2009.

[15] S.-W. Lin and T.-M. Ben, "Impact of government and industrial agglomeration on industrial land prices: A Taiwanese case study," Habitat International, vol. 33, no. 4, pp. 412-418, 2009.

[16] F. Tu, X. Yu, and J. Ruan, "Industrial land use efficiency under government intervention: Evidence from Hangzhou, China," Habitat International, vol. 43, pp. 1-10, 2014.

[17] X. Zhang, Y. Lin, Y. Wu, and M. Skitmore, "Industrial land price between China's Pearl River Delta and Southeast Asian regions: Competition or Coopetition?" Land Use Policy, vol. 61, pp. 575586, 2017.

[18] H. Daquan, W. Wei, D. Teqi, and L. Jinshe, "Assessment of industrial land use intensity: a case study of Beijing economictechnological development area," Chinese Geographical Science, vol. 21, no. 2, pp. 222-229, 2011.

[19] C. S. George and P. S. Samuel, "Chinas land resources and landuse change: insights from the 1996 land survey," Land Use Policy, vol. 20, pp. 87-107, 2003.

[20] W. Kuang, J. Liu, J. Dong, W. Chi, and C. Zhang, “The rapid and massive urban and industrial land expansions in China between 1990 and 2010: A CLUD-based analysis of their trajectories, patterns, and drivers," Landscape and Urban Planning, vol. 145, pp. 21-33, 2016.

[21] Y. Meng, F.-R. Zhang, P.-L. An, M.-L. Dong, Z.-Y. Wang, and T. Zhao, "Industrial land-use efficiency and planning in Shunyi, Beijing," Landscape and Urban Planning, vol. 85, no. 1, pp. 4048, 2008.

[22] M. Song, S. Wang, and K. Wu, "Environment-biased technological progress and industrial land-use efficiency in China's new normal," Annals of Operations Research, pp. 1-16, 2016.

[23] S. Z. Ke and D. L. Yao, "The Causal Relationship and Determinants of Industrial Agglomeration and Urban Labor Productivity," he Journal of Quantitative \& Technical Economics, pp. 3-14, 2008.
[24] C. Long and X. Zhang, "Patterns of China's industrialization: Concentration, specialization, and clustering," China Economic Review, vol. 23, no. 3, pp. 593-612, 2012.

[25] G. Xian and D. Wen, Foreign Openness, Dynamic Externalities and Regional Industrial Growth,Center for Transnational Corporations of Nankai University, 2008.

[26] P. McCann and S. Sheppard, "The rise, fall and rise again of industrial location theory," Regional Studies, vol. 37, no. 6-7, pp. 649-663, 2003.

[27] D. Mccormick, "African enterprise clusters and industrialization: Theory and reality," World Development, vol. 27, no. 9, pp. 1531-1551, 1999.

[28] L. H. Tao and Y. Zhang, "The empirical research on the contribution of high technology industry to the growth of Hubei," Journal of Hubei Administration Institute, vol. 5, pp. 5962, 2007.

[29] A. Kudina and C. Pitelis, "De-industrialisation, comparative economic performance and FDI inflows in emerging economies," International Business Review, vol. 23, no. 5, pp. 887-896, 2014.

[30] H. Xie, W. Wang, Z. Yang, and Y. Choi, "Measuring the sustainable performance of industrial land utilization in major industrial zones of China," Technological Forecasting \& Social Change, vol. 112, pp. 207-219, 2016.

[31] W. Chen, J. C. Peng, and Q. Wu, "Spatial and Temporal Differences in Industrial Land Use Efficiency in China," Resources Science, vol. 36, no. 10, pp. 2046-2056, 2014.

[32] G. C. Guo and Q. Xiong, "Study on the Urban Industrial Land Use Efficiency and Its Influencing Factors in China," China Land Sciences, vol. 28, no. 4, pp. 45-52, 2014.

[33] H. B. Chenery, S. Robinson, and M. Syrquin, Industrialization and growth: a comparative study, Washington, D.C., USA, The Worldbank, 1986.

[34] X. C. Li, S. W. Li, and S. J. Zhang, "Single factor efficiency analysis in high-tech and non-high-tech industry innovative activities," China Industrial Economics, vol. 5, pp. 68-77, 2010.

[35] S. Speelman, M. D’Haese, J. Buysse, and L. D’Haese, “A measure for the efficiency of water use and its determinants, a case study of small-scale irrigation schemes in North-West Province, South Africa," Agricultural Systems, vol. 98, no. 1, pp. 31-39, 2008.

[36] L. James and K. P. Robert, Introduction to Spatial Econometrics, Chapman \& Hall/CRC, London, UK, 2009.

[37] J. P. Elhorst, "Applied spatial econometrics: Raising the bar," Spatial Economic Analysis, vol. 5, no. 1, pp. 9-28, 2010.

[38] W. Y. Chen, F. Z. Hu, X. Li, and J. Hua, "Strategic interaction in municipal governments' provision of public green spaces: A dynamic spatial panel data analysis in transitional China," Cities, vol. 71, pp. 1-10, 2017.

[39] J. P. Elhorst, "Matlab Software for Spatial Panels," International Regional Science Review, vol. 37, no. 3, pp. 389-405, 2014.

[40] Y. Hao, Y. Liu, J.-H. Weng, and Y. Gao, "Does the Environmental Kuznets Curve for coal consumption in China exist? New evidence from spatial econometric analysis," Energy, vol. 114, pp. 1214-1223, 2016. 


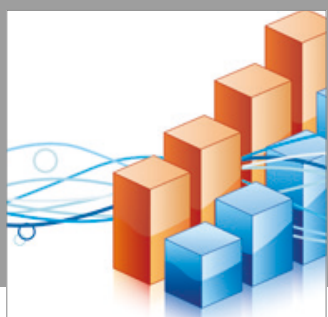

Advances in

Operations Research

vatersals

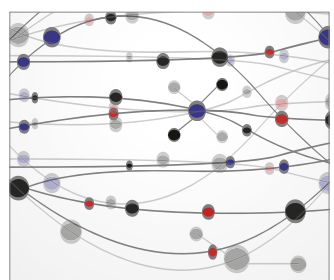

\section{The Scientific} World Journal
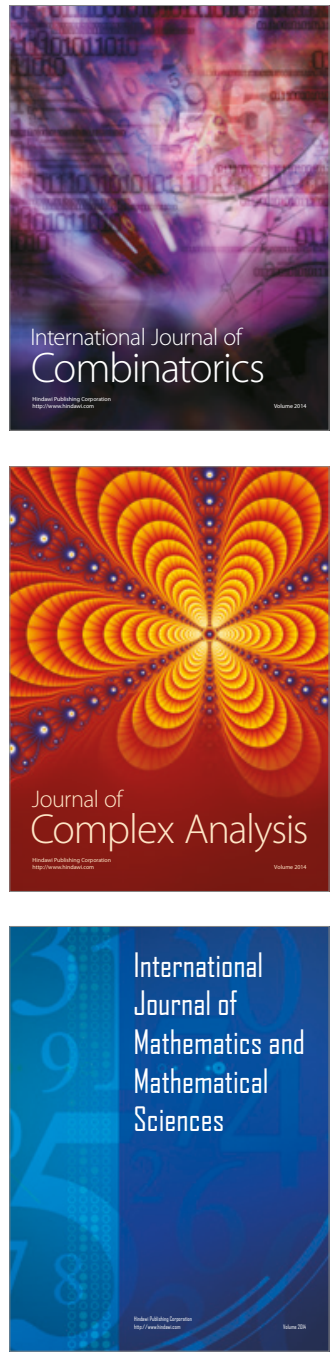
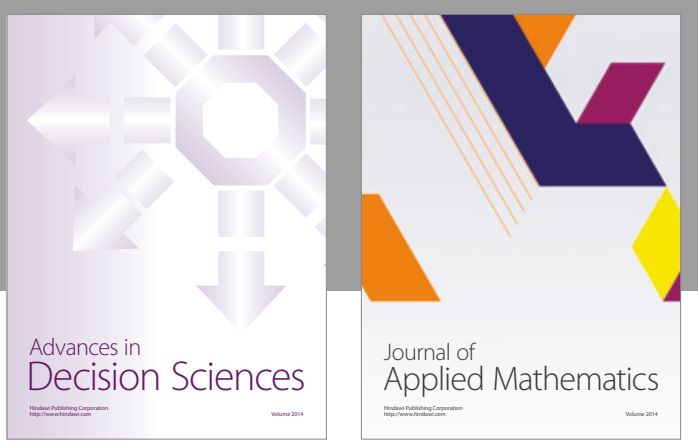

Algebra

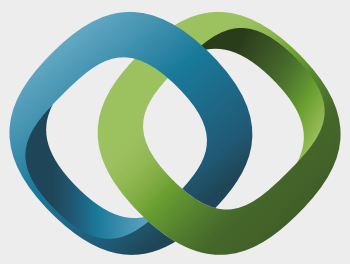

\section{Hindawi}

Submit your manuscripts at

https://www.hindawi.com
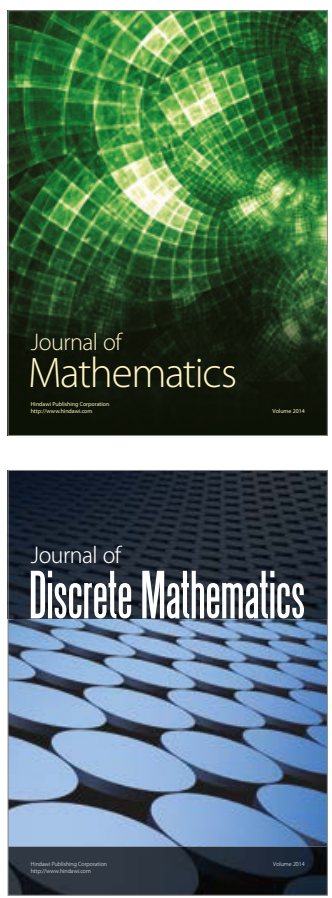

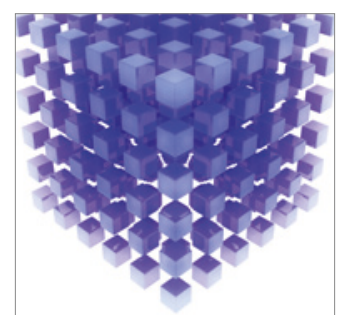

Mathematical Problems in Engineering
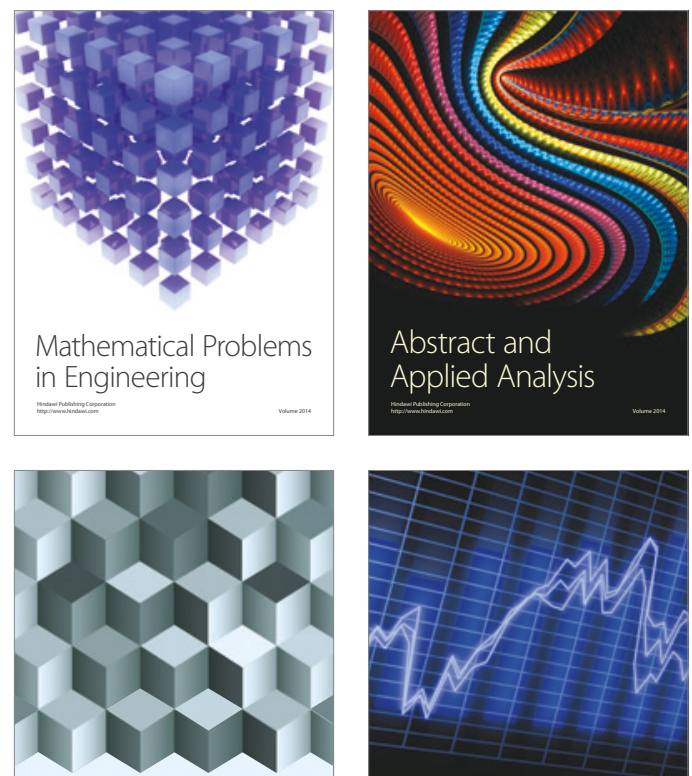

Journal of

Function Spaces

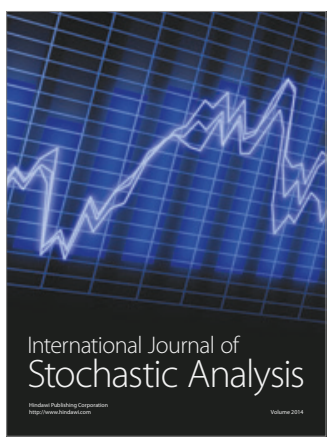

Probability and Statistics
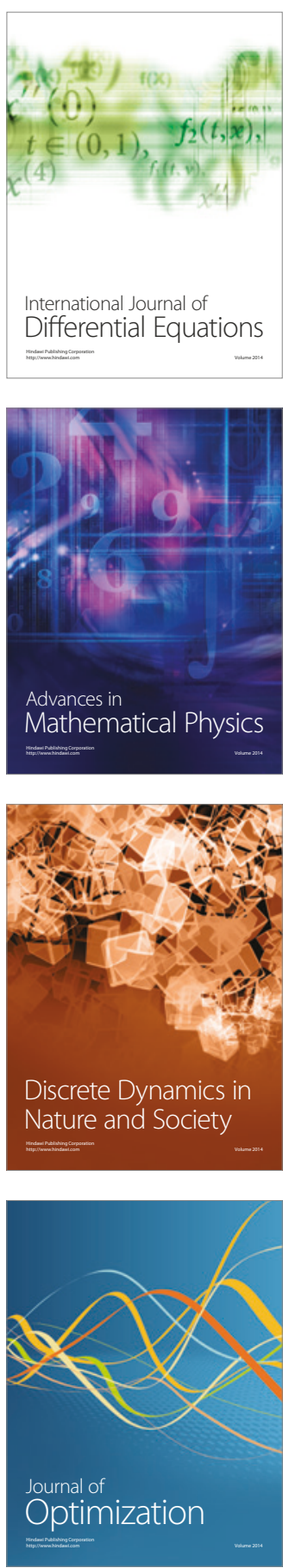